\title{
Theoretical Investigation of Electrophilic Transannular Addition Reactions of Bromine to Face-to-Face (Juxtaposed) Double Bonds in Strained Polycyclic Hydrocarbons
}

\author{
Rza Abbasoglu \\ Department of Chemistry, Karadeniz Technical University, 61080 Trabzon, Turkey \\ * Corresponding author: E-mail: rabbas@ ktu.edu.tr \\ Telephone: +90-462-377-2595, Fax: +90-462-325-319
}

Received: 14-10-2016

\begin{abstract}
Transannular electrophilic addition reaction of halogens to face-to-face(juxtaposed) double bonded strained alkenes were theoretically investigated. General rules that allow us to stipulate the factors that direct the main steps of the energy hypersurface of reactions as well as the products were established. Direction of the reaction flow is determined by direction of intramolecular skeletal isomerisation of cyclic-bridged halogenium cation and isomerisation takes place to create a more stable skeletal structure. Stability of resultant skeletal structure is determined by the number of $\sigma$ bonds between isolated double bonds of the alkene and bonding-type of double bonds ( $\mathrm{N}$ - and U-type). When the number of $\sigma$ bonds between double bonds of the alkene is three $(\mathrm{m}=3)$, the reaction takes place to predominantly give an N-type product, and when four $(\mathrm{m}=4), \mathrm{N}$ - and U-type products are formed. Structure and stability of cation intermediates (bridged, N- and U-type cations) of electrophilic addition reaction of homohipostrofen molecule, whose double bonds were linked by three $\sigma$ bonds, with bromine were investigated by DFT methods in detail. Also the addition reaction of endo,endo-tetracyclo[6.2.2.2. $\left.2^{3,6} .0^{2,7}\right]$ tetradeca-4,9-dien molecule, whose double bonds were linked by four $\sigma$ bonds, with bromine were investigated by quantum chemistry.
\end{abstract}

Keywords: DFT calculations, Strained alkenes, Electrophilic transannular addition, Face-to-face (juxtaposed) double bonds, Intramolecular skeletal rearrangement.

\section{Introduction}

Although theoretical and experimental investigations of the electrophilic additions of halogens to carboncarbon double bond have been carried out extensively, the structure, the nature and the stability of the reaction intermatiates as well as the mechanism of these reactions are still under discussion. The attack of an electrophile to a molecule having two isolated double bonds in spatial proximity usually leads to the transannular bridge formation in either cross (N-type) or parallel (U-type) manner or both. ${ }^{1-4}$ Experimental results on this type of reaction have been confusing. In some cases, only the cross or the parallel bridged product is isolated, while in other cases both products are formed simultaneously. ${ }^{2,3,5-15}$ Recently Inagaki et al. advanced a perturbation theory to interpret those cases where preferential cross bridging takes place. ${ }^{16}$
While the orbital mixing effect must certainly be working when cross bridging occurs, a general theory must explain why and to what extent parallel addition takes place in other systems. Osawa et al. suggested that this was due to the thermodynamic stability of the N- and U-type products. $^{2}$ According to Osawa, it is possible for both products to form when the difference between the thermodynamic stability of $\mathrm{N}$ - and U-type products is less than 10 $\mathrm{kcal} \mathrm{mol}^{-1}$. If the difference is more than $10 \mathrm{kcal} \mathrm{mol}^{-1}$, more stable product is obtained.

In order to learn the inner mechanism and dynamic stereochemistry of these reactions in detail, it is crucial to determine the structure and the stability of the intermediates (cyclic-bridged, $\mathrm{N}$ - and U-type cations) formed during the course of the reaction and investigate their skeletal isomerization. It is feasible for the cyclic bridged halogenium cation to transform into $\mathrm{N}$ - and U-type bridged ca- 
tions as a result of the transannular cross (N-type) and parallel (U-type) linkage of the double bonds. Therefore, the stability of $\mathrm{N}$ - and U-type cations, into which cyclic bridged halogenium cation isomerized, is important in order to ascertain the direction of the flow of the addition reaction.

The structure and the nature of the alkene play an important role in the display of characteristic behavior of the electrophilic addition reactions of the halogens to parallel face-to-face (juxtaposed) double bonded strained alkenes. The investigation of the geometrical and electronical structure of alkenes is necessary to resolve the link between the structure of the alkenes and their behaviors during the electrophilic addition reactions. The study of the stability and stereochemistry of the different configurations of the reaction products is vital so as to interpret the many features of the electrophilic addition reactions.

The objective of this study is to establish relationships between geometric and electronic structures of faceto-face double bonded strained alkenes and their behaviors during electrophilic transannular addition reactions. Furthermore, we aimed to study unique characteristics of these reactions, identify essential factors that determine the direction of reactions' flow and establish general rules that allow us to stipulate the factors that direct the flow of such reactions, and reaction products considering the results of this investigation and structure-characteristic relationships. In order to prove these suggested rules, electrophilic transannular addition reactions of bromine molecule to two face-to-face double bonded strained alkenes, namely tetracyclo[6.3. $\left.0^{4,11} \cdot 0^{5,9}\right]$ undeca-2,6-diene(homohipostrofene) and endo,endo-tetracyclo[6.2.2.2. $\left.2^{3,6} \cdot 0^{2,7}\right]$ tetradeca-4,9-diene(TCTD) were studied by DFT method.

\section{Methodology}

The geometry and the electronic structure of the tetracyclo $\left[6.3 \cdot 0^{4,11} \cdot 0^{5,9}\right]$ undeca-2,6-diene (homohipostrofene) and endo,endo-tetracyclo[6.2.2.2. $\left.2^{3,6} \cdot 0^{2,7}\right]$ tetradeca-4,9diene(TCTD) molecules were investigated by DFT/B3LYP ${ }^{17,18}$ method using the 6-311G $(\mathrm{d}, \mathrm{p})$ and 6$311++\mathrm{G}(\mathrm{d}, \mathrm{p})^{19}$ basis sets. The predicted cationic intermediates and products formed in the addition reactions were investigated using the B3LYP/6-311G $(\mathrm{d}, \mathrm{p})$ method. By using the optimized geometries of cations and products by B3LYP/6-311G $(\mathrm{d}, \mathrm{p})$ method, their single point energies were calculated at the B3LYP/6-311++G $(2 \mathrm{~d}, 2 \mathrm{p}){ }^{19}$ level. Solvent effects were calculated at the same theory level as the optimizations by performing single-point calculations on the optimized structures using the CPCM (conducting polarized continuum model) ${ }^{20,21}$ method (with UAKS cavities $\left.^{22}\right)$ in chloroform $(\varepsilon=4.9)$. All stationary points were characterized by calculating the vibrational frequencies and zero-point vibrational energies have been added for all species. We did not calculate the two TSs of the addi- tion reaction of the intermadiate carbocations because of the complexity of the method; instead we used the energy of the intermediates applying the Hammond-principle to predict the stereoselectivity (ratio of N- and U-type product) of the reaction. The calculations were perfomed with Gaussian $03^{23}$ program with an IBM PC Pentium IV computer.

\section{Results and Discussions}

\section{1. Factors Driving Electrophilic Transannular Addition Reactions of Halogens to Face-to- Face Double Bonded Strained Alkenes and Unique Characteristics of These Reactions}

It is important to investigate stability of cyclic-bridged halogenium cations formed as a result of heterolytic decomposition of alkene...halogen molecular complexes formed during first step of electrophilic addition reaction of halogens to face-to-face double bonded strained alkenes as well as their skeletal isomerisation for determination of addition reaction's mechanism. Direction of the addition reaction's flow is determined by direction of intramolecular skeletal isomerisation(intramolecular rearrangement of bonds) of cyclic-bridged halogenium cation and isomerisation takes place to create a more stable skeletal structure. Moreover, the direction of intramolecular skeletal isomerisation of bridged halogenium ions is determined by stability of $\mathrm{N}$ - and U-type cations formed as a result of cross (N-type) and parallel (U-type) bonding of double bonds. Therefore, the direction of addition reaction is determined by stability of skeletal structure formed as a result of skeletal isomerisation of bridged halogenium cation.

Skeletal isomerisation of bridged halogenium ion by formation of two different new cyclic structures(having different number of carbon atoms) depending on the number of $\sigma$ bonds between double bonds of the alkene and bonding type of such double bonds (Chart). The following chart shows skeletal isomerisation of cyclic bridged halogenium cations and new cyclic structures involved in the molecular structure. Hence, stability of skeletal structure formed by skeletal isomerisation of bridged halogenium cation depends on type and stability of new cyclic structures involved in the molecular system as a result of the isomerisation. On the other hand, type and stability of cyclic structures formed as a result of isomerisation are determined by the number $(\mathrm{m})$ and type of bonding of $\sigma$ bonds between double bonds of the alkene, hence, the structure of the alkene. In the case of alkenes with three $(\mathrm{m}=3) \sigma$ bonds between its double bonds, four-ring structure (cyclobutane ring) and six-ring structure (cyclohexane ring) are obtained as a result of parallel (U-type) bonding of double bonds whereas two five-ring structures (cyclopentane ring) are obtained as a result of cross (N-type) 
bonding (Chart, a). A four-ring structure has high stretching energy so there is a low possibility of formation of U-type cation. Therefore, the possibility of transformation of a cyclic halogenium cation into a U-type cation is low, causing a low possibility that addition reaction will take place over the U-type cation. Compared to a four-ring structure, a five-ring structure has lower stretching energy. Skeletal isomerisation of a cyclic bridged halogenium ion to an $\mathrm{N}$-type cation(having two five-ring structures) has higher possibility. Addition reaction should primarily take place to give $\mathrm{N}$-type cation ( $\mathrm{N}$-type product). In the case of alkenes having four $\sigma(\mathrm{m}=4)$ bonds between its double bonds, a five-ring structure (cyclopentane ring) and a six-ring structure (cycloheptane ring) are obtained as a result of parallel (U-type) bonding of double bonds, and two six-ring structure (cyclohexane ring) are obtained as a result of cross(N-type) bonding(Chart, b). Since there isn't a large difference between stretching energies of resultant structures, the difference between stabilities of U-type cation having five-ring and seven-ring structures and of $\mathrm{N}$ type cation having two six-ring structures should be small. In conclusion, during electrophilic addition reaction of halogens to alkenes having four $\sigma$ bonds between its double bonds, skeletal isomerisation of cyclic bridged halogenium cation should take place to give $\mathrm{N}$ - and U-type cations (Chart, b) and thus $\mathrm{N}$ - and U-type products.

Hence, general rules that allow us stipulate any factors that direct the flow of electrophilic addition reactions of halogens to face-to-face double bonded strained alkenes as well as possible resultant products by considering the abovementioned suggestions, results of calculations $^{24-34}$ and structure-characteristic relationships can be listed as follows:
1. Direction of the reaction's flow is determined by the direction of intramolecular skeletal isomerisation(intramolecular rearrangement of bonds) of cyclic bridged halogenium cation.

2. Intramolecular skeletal isomerisation of cyclic bridged cation takes place to give a more stable skeletal structure.

3. Stability of resultant skeletal structure depends on type (Chart) and stability of new cyclic structures involved in the molecular system as a result of isomerisation.

4. Type and stability of cyclic structures formed as a result of isomerisation are determined by the number of $\sigma$ bonds between double bonds of the alkene and bonding type of double bonds ( $\mathrm{N}$ - and U-type), thus, by the structure of the alkene.

5. Direction of addition reaction is determined by the number of $\sigma$ bonds between isolated double bonds of the alkene: When $m=3$ (Chart, a), the reaction predominantly takes place to give $\mathrm{N}$-type product and when $\mathrm{m}=4$ (Chart,b), to give $\mathrm{N}$ - and U-type products (Abbasoğlu rule). ${ }^{32-34}$

Number of $\sigma$ bonds (m) Bonding type Product

$3 \mathrm{~N} \mathrm{~N}$-type

$4 \mathrm{~N}$ and $\mathrm{U} \mathrm{N}$ - and U-type

These suggested rules are also confirmed by experimental results of transannular electrophilic addition reactions of halogens to face-to-face double bonded strained alkenes..$^{2,3-15}$ It is also vital to theoretically investigate electrophilic addition reactions in order to prove such rules. Therefore, electrophilic addition reactions of bromine to tetracyclo[6.3. $\left.0^{4,11} \cdot 0^{5,9}\right]$ undeca-2,6-diene (homohipostrofene) and endo,endo-tetracyclo $\left[6 \cdot 2 \cdot 2 \cdot 2^{3,6} \cdot 0^{2,7}\right]$ tetradeca-4,9-diene were investigated by DFT method.
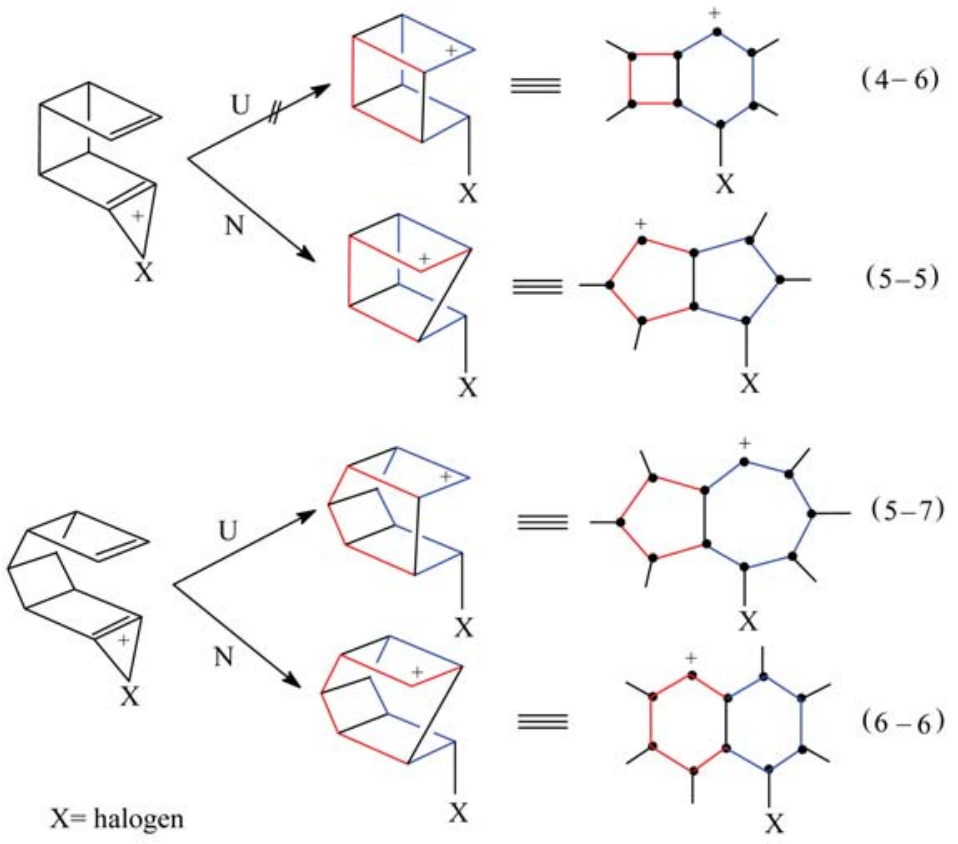

Chart 


\section{2. DFT Study on the Electrophilic Transannular Addition Reaction of Bromine to Tetracyclo[6.3.04,11.05,9] undeca-2,6-diene (Homohipostrofene)}

Bromination of the homohypostrophene molecule (ph) gave only the adduct of N-type (Scheme 1). ${ }^{2,35}$ However, the formation of U-type adduct can't be observed. To identify the reason for this, it is important to study

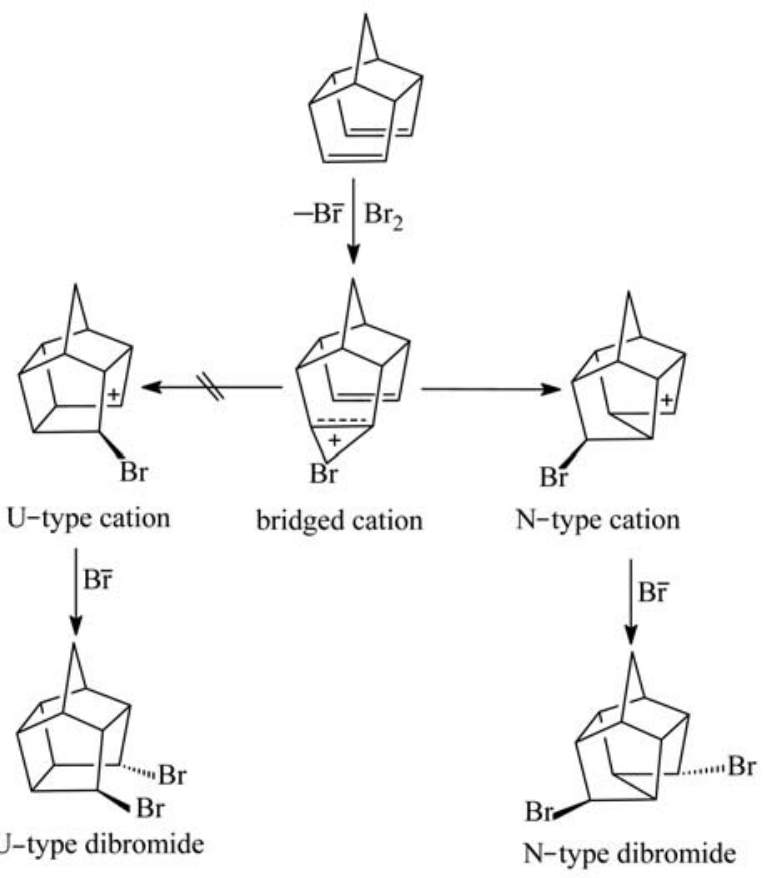

Scheme 1. The electrophilic addition reaction of bromine to $\mathrm{ph}$ structures and stabilities of electrophilic addition reaction intermediates (bridged, $\mathrm{N}$ - and U-type cations) as well as geometric and electron structure of homohipostrofene molecule. Full geometric optimization of the ph was performed by DFT/B3LYP method in 6-311G(d,p) and 6$311++\mathrm{G}(\mathrm{d}, \mathrm{p})$ basis and the structure of the molecule was also investigated in detail.

Bridged cation and its isomers ( $\mathrm{N}$ - and U-type cations) are the possible intermediates of the addition reactions of bromine to ph in gas phase and solvent medium (Scheme 2). The structures and relative stabilities of these cations were determined by carrying out geometrical optimization using the B3LYP/6-311G(d,p) method and the total energies $\left(\mathrm{E}_{\text {tot }}\right)$ were also calculated. By using the optimized geometries of cations at the B3LYP/6-311G(d,p) level, their single point energies have been computed using B3LYP/6-311++G(2d,2p) and CPCM-B3LYP/6$311++\mathrm{G}(2 \mathrm{~d}, 2 \mathrm{p})$ methods. The calculated relative energies are given in Table 1.

According to the results of each method, bridged bromonium cation is more stable than $\mathrm{U}$ type cation and less stable than N-type cation (Table 1). In other words, bridged bromonium cation transforms into more stable $\mathrm{N}$ type cation by cross-bonding (cross mechanism) of the double bonds (Scheme 1). It is not possible for the bridged bromonium cation to isomerizes skeletally to the unstable U-type cation. As a result, the direction of the electrophilic addition reaction of bromine to $\mathrm{ph}$ is determined by the direction of the skeletal isomerization of the bridged bromonium cation into $\mathrm{N}$-type cation and $\mathrm{N}$-type reaction product is prefered to the $\mathrm{N}$-type cation.

The stereochemistry and the stable configurations of the reaction products were investigated by DFT method.
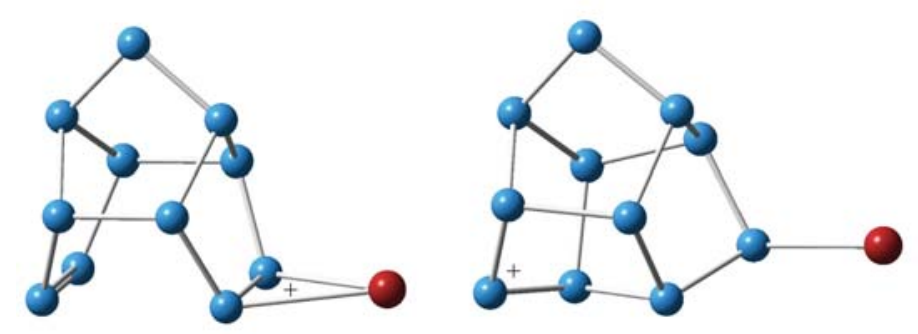

bridged N-type U-type

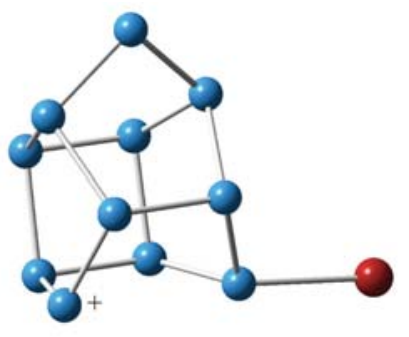

Scheme 2. The optimized geometries of cations (B3LYP/6-311G(d,p))

Table 1. The calculated relative energies of cations Cations Relative energy $\left(\mathrm{kcal} \mathrm{mol}^{-1}\right)$

\begin{tabular}{llll}
\hline & B3LYP/6311 & B3LYP/6311++G(2d,2p) & $\begin{array}{l}\text { CPCM-B3LYP/6311++G(2d,2p) } \\
\text { //B3LYP/6-311G(d,p) }\end{array}$ \\
\hline bridged & G(d,p) & //B3LYP/6-311G(d,p) & 3.926 \\
N-type & 3.485 & 3.242 & 0.0 \\
U-type & 0.0 & 0.0 & 7.252 \\
\hline
\end{tabular}




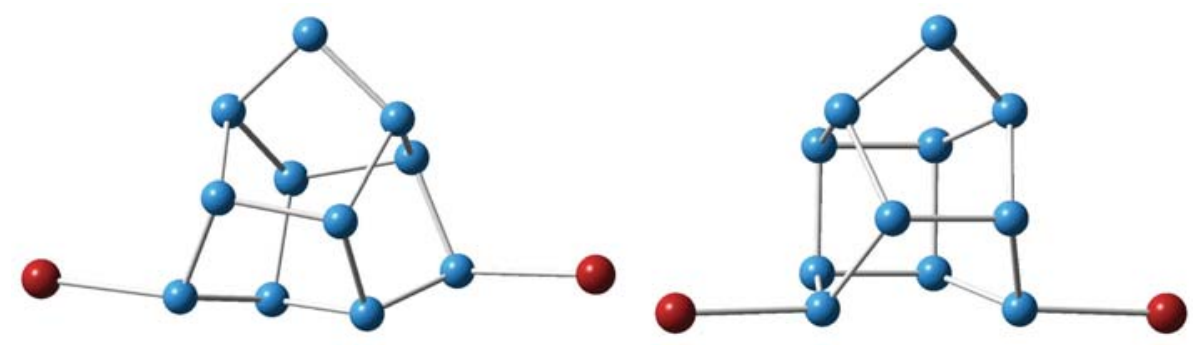

N-type U-type

Scheme 3. The optimized geometries of products (B3LYP/6-311G(d,p))

Table 2. The calculated relative energies of products Products Relative energy $\left(\mathrm{kcal} \mathrm{mol}^{-1}\right)$

\begin{tabular}{llll}
\hline & B3LYP/6311 & B3LYP/6311++G(2d,2p) & CPCM-B3LYP/6311++G(2d,2p) \\
& G(d,p) & //B3LYP/6-311G(d,p) & //B3LYP/6-311G(d,p) \\
\hline N-type & 0.0 & 0.0 & 0.0 \\
U-type & 8.260 & 8.203 & 7.896 \\
\hline
\end{tabular}

The geometrical structure of the N- and U-type products (Scheme 3) were optimized by B3LYP/6-311G(d,p) method and their total energies $\left(\mathrm{E}_{\text {tot }}\right)$ were also calculated. The single point energies of products were calculated by using B3LYP/6-311++G(2d,2p)//B3LYP/6-311G(d,p) and CPCM-B3LYP/6-311++G(2d,2p)//B3LYP/6-311G $(\mathrm{d}, \mathrm{p})$ methods. The calculated relative energies are given in Table 2. According to the results of each method, the N- type dibromide molecule was more stable than U-type dibromide molecule (Table 2).

In other words, parallelism exists between the cation and the corresponding product (Figure 1). In Figure 1, the energy diagram of electrophilic addition reaction of bromine to $\mathrm{ph}$ is given. As can be seen from the energy diagram, the reaction progresses in the direction of the more stable cation and the skeletal isomerisation of the bridged cation

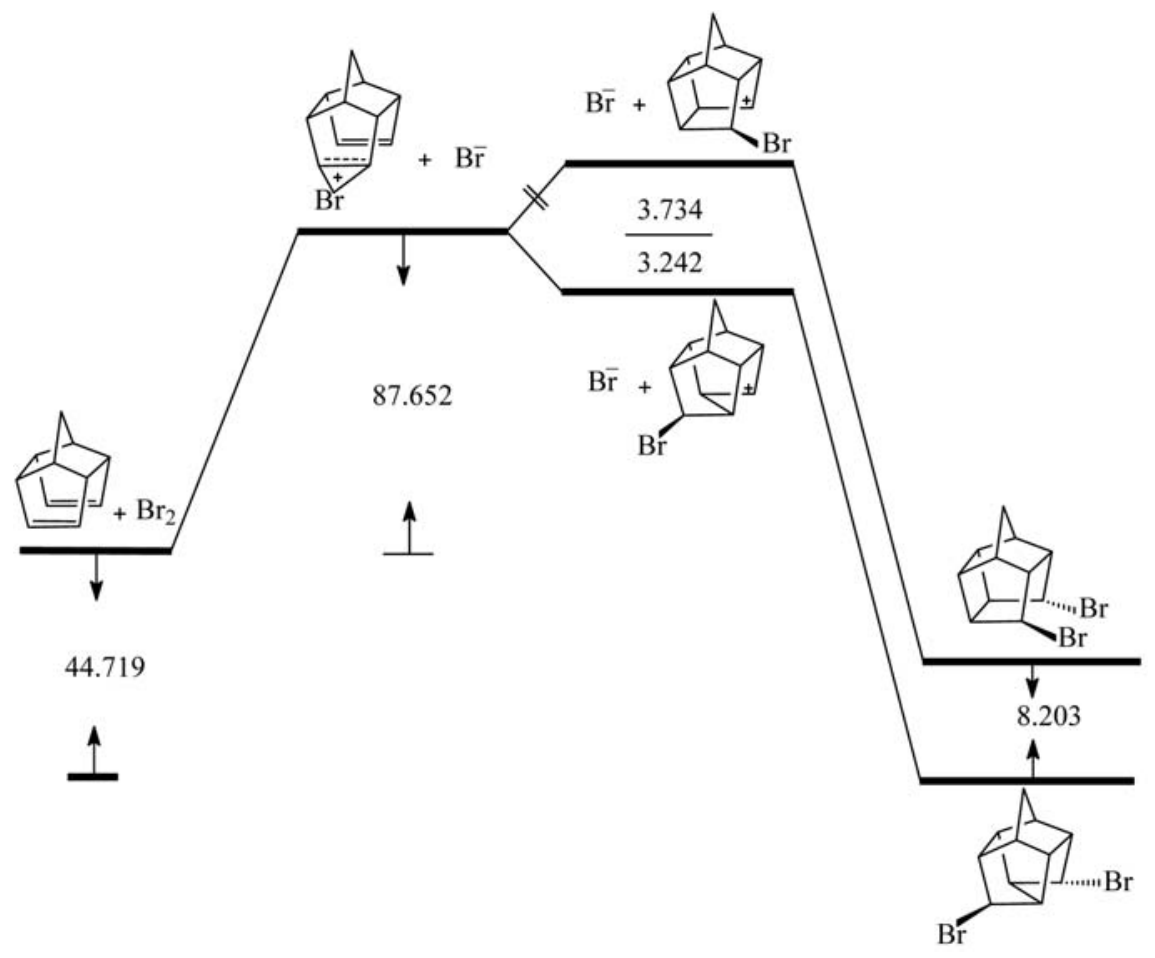

Figure 1. The energy diagram of homohipostrofene- $\mathrm{Br}_{2}$ system $\left(\mathrm{kcalmol}^{-1}\right)$ [B3LYP/6-311++G(2d,2p)//B3LYP/6-311G(d,p)]. 
into $\mathrm{N}$-type cation and finally an $\mathrm{N}$-type product was obtained. Thus, the reaction occurs by the formation of the most stable intermediate combination (N-type cation). In ph, there are three $\sigma$ bonds between double bonds and hence $\mathrm{N}$-type product is obtained. Hence, theoretical investigation results of addition of bromine molecule to homohipostrofen demonstrate accuracy of the abovementioned rules.

\section{3. DFT Investigation of Electrophilic Transannular Addition Reaction of Bromine to Endo,endo-tetracyclo [6.2.2.23,6.02,7]tetradeca-4,9-diene (TCTD)}

A mixture of N-type and U-type products was obtained in the electrophilic addition reaction of bromine to TCTD molecule (Scheme 4) ${ }^{2,36}$ The geometry and the

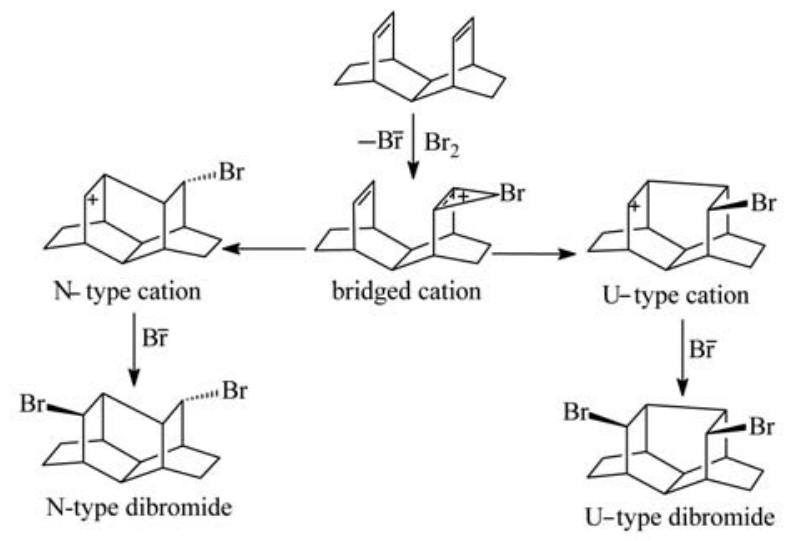

electronic structure of the TCTD molecule were investigated using the B3LYP/6-311G(d,p) and B3LYP/6-311+ $\mathrm{G}(\mathrm{d}, \mathrm{p})$ methods and the structure of the molecule was also investigated in detail.

In order to determine the structures and relative stabilities of the predicted cationic intermediates (bridged, $\mathrm{N}$ - and U-type cations) (Scheme 5) formed in the addition reaction, their full geometry optimization was performed at the B3LYP/6-311G(p,d) level and the total energies $\left(\mathrm{E}_{\text {tot }}\right)$ were also calculated. By using the optimized geometries of cations at the B3LYP/6-311++G(d,p) level, their single point energies were computed using B3LYP/6$311++\mathrm{G}(2 \mathrm{~d}, 2 \mathrm{p})$ and CPCM-B3LYP/6-311++G(2d,2p) methods. The calculated relative energies are given in Table 3.

The results of each method showed that the N- and U-type cations are more stable than the bridged bromonium cation. The skeletal isomerization of the bridged bromonium cation into $\mathrm{N}$ - and U-type cations is thermodynamically feasible. The total energies of $\mathrm{N}$ - and $\mathrm{U}$ type cations differ little and their stabilities are nearly the same. Hence, the bridged bromonium cation transforms into appropriate $\mathrm{N}$ - and $\mathrm{U}$-type cations as a result of skeletal isomerization, where crosswise and parallel mechanisms take place. The direction of the addition reaction is determined by the direction of the rearrangement of the bridged bromonium ion into $\mathrm{N}$ - and U-type cations. The reaction takes place over the $\mathrm{N}$ - and U-type cations in the parallel direction and finally, the $\mathrm{N}$ - and U-type reaction products are obtained. In TCTD molecule, there are four $\sigma$ bonds between double bonds and hence $\mathrm{N}$ - and U-type products are obtained. Hence, the results of DFT investigation of addition of bromine molecule to TCTD molecule prove accuracy of the abovementioned rules.

Scheme 4. The electrophilic addition reaction of bromine to TCTD molecule
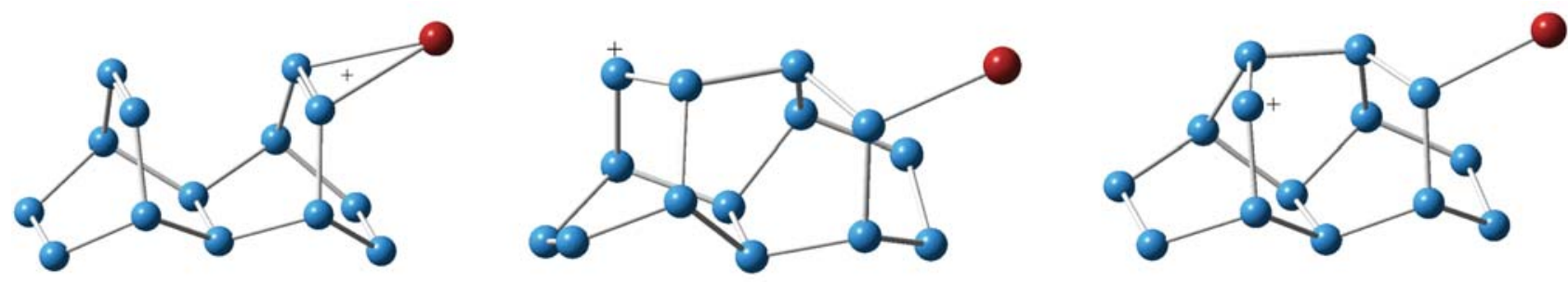

bridged N-type U-type

Scheme 5. The optimized geometries of cations (B3LYP/6-311G(d,p))

Table 3. The calculated relative energies of cations

\begin{tabular}{|c|c|c|c|}
\hline \multirow[t]{2}{*}{ Cations } & \multicolumn{3}{|c|}{ Relative energy $\left(\mathrm{kcal} \mathrm{mol}^{-1}\right)$} \\
\hline & $\begin{array}{l}\text { B3LYP/6311 } \\
\text { G(d,p) }\end{array}$ & $\begin{array}{c}\text { B3LYP/6311++G(2d,2p) } \\
\text { //B3LYP/6-311G(d,p) }\end{array}$ & $\begin{array}{c}\text { CPCM-B3LYP/6311++G(2d,2p) } \\
\text { //B3LYP/6-311G(d,p) }\end{array}$ \\
\hline bridged & 6.253 & 5.525 & 8.876 \\
\hline N-type & 0.0 & 0.0 & 0.0 \\
\hline U-type & 1.003 & 0.590 & 0.154 \\
\hline
\end{tabular}



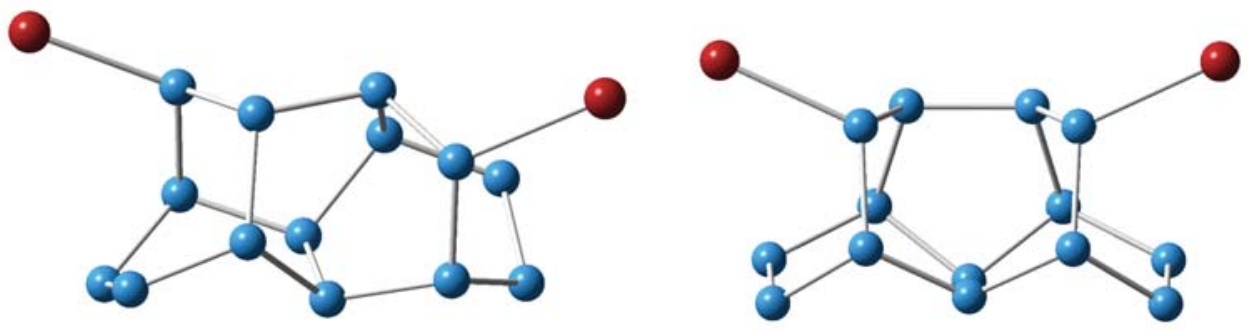

N-type U-type

Scheme 6. The optimized geometries of products (B3LYP/6-311G(d,p))

Table 4. The calculated relative energies of products Product Relative energy $\left(\mathrm{kcal} \mathrm{mol}^{-1}\right)$ )

\begin{tabular}{llll}
\hline & $\begin{array}{l}\text { B3LYP/6311 } \\
\text { G(d,p) }\end{array}$ & $\begin{array}{l}\text { B3LYP/6311++G(2d,2p) } \\
\text { //B3LYP/6-311G(d,p) }\end{array}$ & $\begin{array}{l}\text { CPCM-B3LYP/6311++G(2d,2p) } \\
\text { //B3LYP/6-311G(d,p) }\end{array}$ \\
\hline N-type & 0.0 & 0.0 & 0.0 \\
U-type & 3.601 & 3.977 & 3.733 \\
\hline
\end{tabular}

The stereochemistry and the stable configurations of the reaction products were investigated by DFT method. The geometrical structure of the $\mathrm{N}$ - and U-type products (Scheme 5) were optimized by B3LYP/6-311G(d,p) method and their total energies were evaluated. By using the optimized geometries of products by B3LYP/6-311G(d,p) method, their single point energies were calculated at the B3LYP/6-311++G(2d, 2p) and CPCM-B3LYP/6311 $++\mathrm{G}(2 \mathrm{~d}, 2 \mathrm{p})$ levels. The calculated relative energies are given in Table 4.

Figure 2 shows the energy diagram of the electrophilic addition reaction of bromine to TCTD molecule. As seen from the diagram, the reaction takes place by the transformation of the bridged bromonium cation into the $\mathrm{N}$ - and U-type cations. As the reaction progresses over the $\mathrm{N}$ - and U-type cations, the $\mathrm{N}$ - and U-type products are obtained. The stabilities of the $\mathrm{N}$ - and U-type cation differ little and the stabilities of the $\mathrm{N}$ - and U-type products are very close to each other.

\section{Conclusions}

General rules that allow us to stipulate the factors that direct the flow of electrophilic addition reactions of halogens to face-to-face double bonded strained alkenes

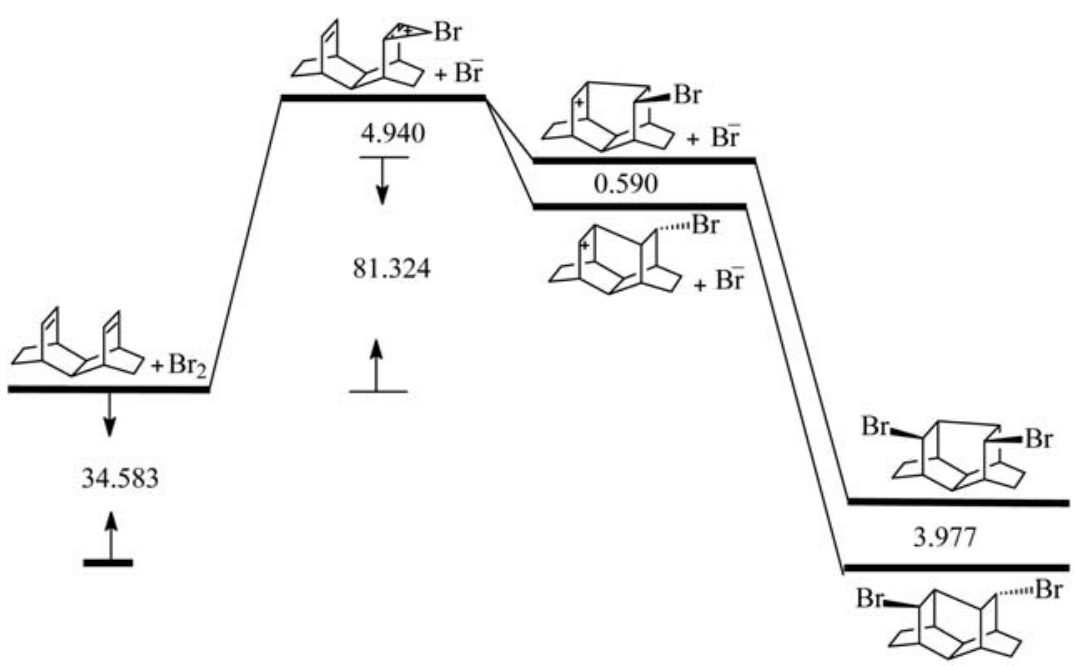

Figure 2. The energy diagram of TCTD-Br $r_{2}$ system $\left(\mathrm{kcal} \mathrm{mol}^{-1}\right)$ [B3LYP/6-311++G(2d,2p)//B3LYP/6-311G(d,p)] (The formations of N- and Utype products are controlled by the relative energy of $\mathrm{N}$ - and $\mathrm{U}$-type cationic intermadiates. And also, both products are formed because the relative energies of the cations intermediates are low.) 
and reaction products were established by considering the results of the calculations and structure-characteristic relationships. Direction of the addition reaction is determined by direction of isomerisation of bridged halogenium cation and isomerisation takes place to create a more stable skeletal structure. Stability of resultant skeletal structure depends on types and stability of new cyclic structures. Stability of resultant new cyclic structures are determined by the number of $\sigma$ bonds between isolated double bonds of the alkene and bonding-type of double bonds ( $\mathrm{N}$ - and U-type), hence by the structure of alkene. When the number of $\sigma$ bonds between double bonds of the alkene is three $(m=3)$, the reaction takes place to predominantly give an N-type product, and when four $(\mathrm{m}=$ 4), N- and U-type products. Structure and stability of cation intermediates of electrophilic addition reaction of bromine to homohipostrofen molecule having double bonds with three $\sigma$ bonds inbetween, were investigated by DFT methods in detail. The reaction takes place over more stable N-type cation which bridged bromonium cation isomerizes into to give $\mathrm{N}$-type dibromide product. Addition reaction of bromine to endo,endo-tetracyclo $\left[6.2 .2 .2^{3,6} \cdot 0^{2,7}\right]$ tetradeca-4,9-dien molecule, whose double bonds were linked by four $\sigma$ bonds, was investigated by quantum chemistry. Bridged bromonium cation isomerizes into more stable $\mathrm{N}$ - and $\mathrm{U}$-type cations and the reaction takes place over these cations to give $\mathrm{N}$ - and U-type dibromide products.

\section{References}

1. C. T. Lin, N. J. Wang, H. Z. Tseng, T. C. Chou, J. Org. Chem. 1997, 62, 4857-4861. https://doi.org/10.1021/jo970299c

2. E. Osawa, K. Aigami, Y. Inamoto, Tetrahedron 1978, 34, 509-515. doi:.org/10.1016/0040-4020(78)00044-1

3. C. T. Lin, N. J. Wang, Y. L. Yhe, T. C. Chou, Tetrahedron, 1995, 51, 2907-2928. https://doi.org/10.1016/0040-4020(95)00044-6

4. C. T. Lin, H. C. Hsu, T. C. Chou, J. Org. Chem. 1999, 64, 7260-7264. https://doi.org/10.1021/jo990569m.

5. T. Sasaki, K. Kanematsu, A. Kondo, J. Org. Chem. 1974, 39 , 2246-2251. https://doi.org/10.1021/jo00929a025

6. M. G. Matturro, R. D. Adams, K. B. Wiberg, Chem. Commun. 1981, 17, 878-879.

https://doi.org/10.1039/c39810000878

7. S. Uemura, S. Fukuzawa, A. Toshimitsu, O. Masaya, J. Org. Chem. 1983, 48, 270-273

https://doi.org/10.1021/jo00150a029

8. K. B. Wiberg, R. D. Adams, P. J. Okarma, M. G. Matturro, B. Segmýller, J. Am. Chem. Soc. 1984, 106, 2200-2206. https://doi.org/10.1021/ja00319a048

9. M. Kimura, S. Morossawa, J. Org. Chem. 1985, 50, 15321534. https://doi.org/10.1021/jo00209

10. K. J. Shea, A. C. Greeley, S. Nguyen, P. D. Beauchamp, D. H. Aue, J. S. Witzeman, J. Am. Chem. Soc. 1986, 108, 5901-
5908. https://doi.org/10.1021/ja00279a040

11. G. Haufe, G. Alvernhe, A. Laurent, Tetrahedron Lett. 1986, 27, 4449-4452.

https://doi.org/10.1016/S0040-4039(00)84975-8

12. C. H. Lee, S. Liang, T. Haumann, R. Boese, A. de Meijere, Angew. Chem. Int. Edit. Engl. 1993, 32, 559-560. https://doi.org/0570-0833/93/0404-0559

13. R. Pinkos, J. P. Melder, K. Weber, D. Hunkler, H. Prinzbach, J. Am. Chem. Soc. 1993, 115, 7173-7191.

https://doi.org/10.1021/ja00069a015

14. R. E. Robinson, D. Y. Myers, Tetrahedron Lett. 1999, 40, 1099-1100.

https://doi.org/10.1016/S0040-4039 (98)08843-4

15. D. D. Günbaş, F. Algý, T. Hökelek, W. H. Watson, M. Balcý, Tetrahedron 2005, 61, 11177-11183. https://doi.org/10.1016/j.tet.2005.09.019

16. S. Inagaki, H. Fujimoto, K. Fukui, J. Am. Chem. Soc. 1976, 98, 4054-4061. https://doi.org/10.1021/ja00430a006

17. C. Lee, W. Yang, R. G. Parr, Phys. Rev. B 1988, 37, 785-789. https://doi.org/10.1103/PhysRevB.37.785

18. A. D. Becke, J. Chem. Phys. 1993, 98, 5648-5652. https://doi.org/10.1063/1.46491319

19. R. Krishnan, J. S. Binkley, R. Seeger, J. A. Pople, J. Chem. Phys. 1980, 72, 650-654.

https://doi.org/10.1063/1.438955

20. V. Barone, M. Cossi, J. Phys. Chem. A 1998, 102, 19952001. https://doi.org/10.1021/jp9716997

21. J. Tomasi, B. Mennucci, R. Cami, Chem. Rev. 2005, 105, 2999-3093. https://doi.org/10.1021/cr9904009

22. Y. Takano, K. N. Houk, J. Chem. Theory Comput. 2005, 1, 70-77. https://doi.org/10.1021/ct049977a

23. M. J. Frisch, G. W. Trucks, H. B. Schlegel, G. E. Scuseria, M. A. Robb, J. R. Cheeseman, J. A. J. Montgomery, T. Vreven, K. N. Kudin, J. C. Burant, J. M. Millam, S. S. Iyengar, J. Tomasi, V. Barone, B. Mennuci, M. Cossi, G. Scalmani, N. Rega, G. A. Petersson, H. Nakatsuji, M. Hada, M. Ehara, K. Toyota, R. Fukuda, J. Hasegawa, M. Ishida, T. Nakajima, Y. Honda, O. Kitao, H. Nakai, M. Klene, X. Li, J. E. Knox, H. P. Hratchian, J. B. Cross, C. Adamo, J. Jaramillo, R. Gomperts, R. E. Stratmann, O. Yazyev, A. J. Austin, R. Cammi, C. Pomelli, J. W. Ochterski, P. Y. Ayala, K. Morokuma, G. A. Voth, P. Salvador, J. J. Dannenberg, V. G. Zakrzewski, S. Dapprich, A. D. Daniels, M. C. Strain, O. Farkas, D. K. Malick, A. D. Rabuck, K. Raghavachari, J. B. Foresman, J. V. Ortiz, Q. Cui, A. Baboul, G. S. Clifford, J. Cioslowski, B. B. Stefanov, G. Liu, A. Liashenko, P. Piskorz, I. Komaromi, R. L. Martin, D. J. Fox, T. Keith, M. A. Al-Laham, C. Y. Peng, A. Nanayakkara, M. Challacombe, P. M. W. Gill, B. Johnson, W. Chen, M. W. Wong, C. Gonzalez, J. A. Pople, Gaussian 03, Revison B.03, Gaussian, Pittsburgh, PA., 2003.

24. R. Abbasoglu, J. Mol. Model. 2006, 12, 991-995. https://doi.org/10.1007/s00894-006-0113-3

25. R. Abbasoglu, J. Mol. Model. 2007, 13, 425-430. https://doi.org/10.1007/s00894-006-0161-8

26. R. Abbasoglu, J. Mol. Model. 2007, 13, 1215-1220. https://doi.org/10.1007/s00894-007-0236-1 
27. R. Abbasoglu, A. Magerramov, Acta Chim. Slov. 2007, 54 , 882-887.

28. R. Abbasoglu, Y. Uygur, Indian J. Chem. A 2007, 46A, 396400.

29. R. Abbasoglu, J. Mol. Model. 2009, 15, 397-403. https://doi.org/10.1007/s00894-008-0388-7

30. R. Abbasoglu, A. Magerramov, Y. Aşamaz, Acta Chim. Slov. 2009, 56, 237-245.

31. R. Abbasoglu, A. Yasar, Turk J. Chem. 2010, 34, 127-134. https://doi.org/10.3906/kim-0812-14
32. R. Abbasoglu, Y. Așamaz, A. Magerramov, E. Mamedov, THEOCHEM 2010, 955, 130-133. https://doi.org/10.1016/j.theochem.2010.06.005

33. R. Abbasoglu, Acta Chim. Slov. 2010, 57, 842-848.

34. R. Abbasoglu, M. N. Misir, Acta Chim. Slov. 2012, 59, 109116.

35. G. R. Underwood, B. Ramamoorthy, Tetrahedron Lett. 1970, $11,4125-4127$. https://doi.org//10.1016/S0040-4039(01) 98683-6

36. E. LeGoff, S. Oka, J. Am. Chem. Soc. 1969, 91, 5665-5667. https://doi.org/10.1021/ja01048a054

\section{Povzetek}

Teoretično smo proučevali elektrofilno adicijo halogenov na sosednja mesta v alkenih. Določili smo splošna pravila, ki nam omogočajo določanje dejavnikov pri usmerjanju glavnih stopenj te reakcije. Ugotovili smo, da je smer reakcije odvisna od usmerjenosti intramolekularne skeletne izomerizacije ciklično premoščenega halogenskega kationa. Izomerizacija poteče tako, da nastane bolj stabilna skeletna struktura. Njeno stabilnost smo določili s številom $\sigma$ vezi med izoliranimi dvojnimi vezmi v alkenu in dvojnimi vezmi $\mathrm{N}$ - in U-tipa. Če je število $\sigma$ vezi med dvojnimi vezmi v alkenu tri $(\mathrm{m}=3)$, reakcija poteka pretežno tako, da dobimo produkt $\mathrm{N}$-tipa, pri $\mathrm{m}=4$ pa nastanejo produkti $\mathrm{N}$ - in U-tipa. Strukturo in stabilnost kationskih intermediatov (premoščen, N in U-tip) pri elektrofilni adiciji smo natančno preučili z metodo DFT. 